\title{
The family experiences of in-hospital care questionnaire in severe traumatic brain injury (FECQ-TBI): a validation study
}

\author{
Audny Anke ${ }^{1,2^{*}}$, Unn Sollid Manskow ${ }^{1,3}$, Oddgeir Friborg ${ }^{4}$, Cecilie Røe $e^{5,6}$ and Cathrine Arntzen ${ }^{1,3}$
}

\begin{abstract}
Background: Family members are important for support and care of their close relative after severe traumas, and their experiences are vital health care quality indicators. The objective was to describe the development of the Family Experiences of in-hospital Care Questionnaire for family members of patients with severe Traumatic Brain Injury (FECQTBI), and to evaluate its psychometric properties and validity.
\end{abstract}

Methods: The design of the study is a Norwegian multicentre study inviting 171 family members. The questionnaire developmental process included a literature review, use of an existing instrument (the parent experience of paediatric care questionnaire), focus group with close family members, as well as expert group judgments. Items asking for family care experiences related to acute wards and rehabilitation were included. Several items of the paediatric care questionnaire were removed or the wording of the items was changed to comply with the present purpose. Questions covering experiences with the inpatient rehabilitation period, the discharge phase, the family experiences with hospital facilities, the transfer between departments and the economic needs of the family were added. The developed questionnaire was mailed to the participants. Exploratory factor analyses were used to examine scale structure, in addition to screening for data quality, and analyses of internal consistency and validity.

Results: The questionnaire was returned by 122 (71\%) of family members. Principal component analysis extracted six dimensions (eigenvalues > 1.0): acute organization and information (10 items), rehabilitation organization (13 items), rehabilitation information ( 6 items), discharge (4 items), hospital facilities-patients (4 items) and hospital facilities-family (2 items). Items related to the acute phase were comparable to items in the two dimensions of rehabilitation: organization and information. All six subscales had high Cronbach's alpha coefficients $>0.80$. The construct validity was confirmed.

Conclusion: The FECQ-TBI assesses important aspects of in-hospital care in the acute and rehabilitation phases, as seen from a family perspective. The psychometric properties and the construct validity of the questionnaire were good, hence supporting the use of the FECQ-TBI to assess quality of care in rehabilitation departments.

Keywords: Parent satisfaction, Patient satisfaction, Family satisfaction, Quality of care, Traumatic brain injury, Rehabilitation

\footnotetext{
* Correspondence: audny.anke@uit.no

'Department of Rehabilitation, University Hospital of North Norway,

Sykehusvn.1, 9038 Tromsø, Norway

${ }^{2}$ Faculty of Health Sciences, Department of Clinical Medicine, UiT The Arctic

University of Norway, Tromsø, Norway

Full list of author information is available at the end of the article
} 


\section{Background}

The family perspective in health care after injuries is recognized as increasingly important and a vital health care indicator [1]. In patients with memory and communication problems experiences of the family members are key dimensions of health care quality, as relatives play a role in care and support and often act as the patient's representative [2]. After traumatic brain injuries spouses and parents are the most frequent caregivers $[3,4]$ and may have specific post-trauma experiences and needs [4-6] that change across the treatment phases [7-9]. However, multidimensional scales evaluating care experiences and satisfaction with acute care and rehabilitation after traumatic brain injuries in adult caregivers are not available.

Patients' experiences and satisfaction with health care services are linked to important aspects of quality of care such as patient adherence to treatment, patient safety and clinical effectiveness [10, 11]. Several national surveys in Norway have described the systematic development and validation of questionnaires related to patients' experiences [12-14]. The concepts of satisfaction and experiences are positively related and often used interchangeably [14]. Asking patients about their specific experience with concrete events is more valid and easier to interpret than satisfaction ratings $[13,15,16]$. The evidence-based knowledge of patients' treatment experiences following severe traumatic brain injury (TBI) is limited $[17,18]$ Important areas for quality of care include information from staff and the organization of services. Furthermore, studies using qualitative methodologies have identified interdepartmental transitions between acute care and inpatient rehabilitation, and the discharge period from hospital, as particularly challenging factors $[7,19]$.

There are family satisfaction questionnaires for use in the intensive care units [2, 20, 21], and parents' views have been increasingly used in the evaluation of care quality for children $[22,23]$. Theoretically close relatives to surviving injured patients have comparable inhospital experiences to parents with chronically ill children, so we searched for a suitable parent experience instrument covering multiple dimensions of care. Based on a literature review, the carefully constructed and validated multidimensional parent experience of paediatric care (PEPC) questionnaire [22] represent a suitable starting point for the present development of a questionnaire evaluating family experiences of care after TBI. An intention, not covered in the PEPC questionnaire, was to evaluate separately the acute care and the inpatient rehabilitation phases, and to use a multidisciplinary approach with information about experiences with "staff" rather than "nursing" and "doctor services". Moreover the development of questionnaires for new groups must incorporate their specific experiences, which focus group interviews may provide [13].
Accordingly, the main aim of this study was to describe the developmental process and to psychometrically evaluate a questionnaire that assesses treatment and rehabilitation experiences of the family members of patients with severe TBI. An intention was to record quality of care experiences separately for different phases of care to be able to make relevant comparisons. The questionnaire was named the family experiences of in-hospital care questionnaire in severe traumatic brain injury (FECQ-TBI), and was evaluated with regard to data quality, factor and scale structure, internal consistency and construct validity.

Based on previous literature on satisfaction with care, including the experiences and satisfaction of relatives (parents), we expected the subscales of the present instrument to be positively and significantly correlated, as experiences with the organization, information and preparation for discharge reflect different but related dimensions of quality of care. Also experiences with hospital facilities were expected to show positive correlations with the other subscales. As all the subscales in the instrument represent aspects of quality of care, positive correlations were hypothesised to exist between subscales and overall satisfaction with care, treatment and rehabilitation. Negative correlations were hypothesised to exist between single-item questions assessing the extent of any incorrect treatment or experiences of problems/disappointments with staff and the subscales regarding experiences with organization and information [22-24]. Finally, as a part of the test of construct validity, the age of the patients was hypothesised to be unrelated to the FECQ-TBI subscales [25].

\section{Methods}

To ensure the content validity in the questionnaire developmental process, items from previous questionnaires assessing the experience of in-hospital patients [12-14] and parents $[22,23]$ were consulted. Further, selection of items was based on interviews with family members and the expert knowledge of the authors (i.e., UMS, CA and AA) on rehabilitative care after severe TBI or other acquired brain injuries. The psychometric evaluation of the new questionnaire used the COnsensus-based Standards for the selection of health status Measurement Instruments (COSMIN) [26] checklist as a guideline.

\section{Questionnaire development - the starting point}

Following a literature search, the PEPC questionnaire developed by Garratt et al. [22] represented a good starting point for the present FECQ-TBI as it was found to be well validated, not disease specific, and available in Norwegian. The PEPC questionnaire contains 25 questions covering six subscales: organization, information about examinations and tests, doctor services, nursing services, information about discharge and hospital facilities. In addition, included in the PEPC questionnaire was several other single 
questions of possible interest in the family experiences questionnaire developmental process: nine questions about health care delivery, overall satisfaction with care and how the parents were treated, the extent to which parent expectations were met, information about medication, extent of poor treatment, and extent of any problems with the staff. Good validity, internal consistency and test-retest reliability have been reported $[22,27]$.

\section{Focus group}

The original PEPC questionnaire was modified for use in the present study after using a focus group approach with three caregivers of patients with severe TBI in northern Norway who had received inpatient rehabilitation. Focus group sizes are usually between 4 and 12 participants per group [28]. The caregivers differed with respect to strategically important aspects such as caregivers' age and relationship to patient, and patient-related aspects such as type and severity of injury. A focus group is useful for generating indepth information about the phenomena relevant for the particular study objective $[29,30]$ such as questionnaire construction. Caregivers' experiences provide knowledge that through systematic exploration and comparison may contribute to achieve conceptual clarity or identify new conceptual issues $[29,30]$. The method is also suitable for examining whether the questionnaire items are appropriately formulated. An interview guide was developed (by authors CA and AA). The interview lasted approximately two hours and was led by a qualified researcher (CA). The interview was audiotaped and one observer (AA) wrote detailed notes throughout the session. The interview included a presentation of the purpose of the interview and an invitation for family members to briefly introduce themselves. The researcher then facilitated a discussion of topics related to treatment phases (acute care, rehabilitation, discharge) using open-ended questions regarding experiences with the staff (e.g., stability, information), good and bad experiences, issues related to safety and trust regarding the treatment quality, areas of high satisfaction, missing health care services, the hospital facilities and preparations for discharge. Lastly, the family members were asked for advice on how to improve the services.

\section{The new family experiences of care questionnaire in traumatic brain injury (version 1)}

Detailed notes from the focus group interview were systematically processed and categorised and the themes that emerged were checked against the items in the PEPC questionnaire. Items that covered important areas were kept in the new questionnaire, often with slight modifications to be suitable. A small pilot study $(n=3)$ of the questionnaire was conducted in which the family members of the focus group commented on the relevance and intelligibility of the questions and evaluated the rated response options on each item. After small changes in wording and the removal of one item, the complete questionnaire yielded 55 items and was named the FECQ-TBI (version 1). Fifty-one items were related to experiences with or satisfaction with care, while four items were yes/no questions asking separately about 1) whether a patient intended diary were used, and 2) whether children were involved, within the acute department and the rehabilitation department, respectively.

Table 1 summarises the 51 care experiences items in the mailed questionnaire (version 1). For each item the corresponding scale in the PEPC questionnaire is given (Table 1 , 3rd column, PEPC scale given in table subtext). Some of the questions were modified in the FECQ-TBI; the most frequent modifications of phrases in the FECQ-TBI are the changes from nurse or doctor to staff and from child to patient. For instance, in the PEPC questionnaire, "Nursing staff caring for child" and "Doctors caring for child" are replaced in the FECQ-TBI with "Staff caring for patient". The 11 questions regarding the acute phase/department were asked with identical phrasing regarding the rehabilitation department. An additional nine items were added regarding experiences with the rehabilitation department as a result of the focus group interview (rehab department items 12-20). New items emerging from the focus group interview were also added to the original PEPC scales discharge-information and hospital facilities. Based on theoretical considerations of distinct concepts, the items relating to discharge and to hospital facilities were analysed as distinct concepts (see Statistics). As illustrated in Table 1, four of the overall single-item questions were identical to the overall questions in the PEPC questionnaire, and three were added in this study: regarding transfer between departments, economical needs and care of involved children. These overall single-item questions were not suitable for factor analysis, as they were never meant to be included in factors or scales [12, 13, 22].

The original scoring method was preserved. Each item was scored from 1 (worst experience) to 5 (best experience). Items related to experiences with the provided health care ranged from 1-not at all to 5-to a very large extent. Negative items were re-coded before summation; thus, a higher score represents better experience. The questionnaire did not include an opportunity to respond "not applicable".

\section{Data collection}

The self-administered FECQ-TBI (version 1) was mailed to 171 family members of patients with severe TBI who were injured between 2009 and 2011 and who participated in a Norwegian multicentre study [31]. Data were collected from family members 3 and 12 months after injury for patients injured in 2010 and only 12 months after injury for other patients. In the family experiences of care study, data collected 12 months after injury were preferred. 
Table 1 Overview of the 51 items divided in main areas and illustrating the corresponding questions asked about the acute and rehabilitation departments (version 1 questionnaire)

\begin{tabular}{|c|c|c|c|c|c|c|c|c|}
\hline & \multicolumn{2}{|l|}{ Items } & \multicolumn{3}{|c|}{ Rehab department items } & \multicolumn{3}{|c|}{ Acute department items } \\
\hline & & $\begin{array}{l}\text { PEPC } \\
\text { Item }^{c}\end{array}$ & $\begin{array}{l}\text { Missing } \\
\mathrm{n}(\%)^{\mathrm{b}}\end{array}$ & Mean $^{a}$ & $\overline{S D}$ & $\begin{array}{l}\text { Missing } \\
\mathrm{n}(\%)^{\mathrm{b}}\end{array}$ & Mean $^{a}$ & SD \\
\hline 1 & One doctor mainly responsible & $\mathrm{O}$ & $4(3.5)$ & 3.86 & 1.11 & $2(1.6)$ & $3.39^{\mathrm{e}}$ & 1.25 \\
\hline 2 & Fixed group nurses & $\mathrm{O}$ & $4(3.5)$ & 3.92 & 0.98 & $2(1.6)$ & 3.85 & 0.99 \\
\hline 3 & Staff collaboration & $\mathrm{O}$ & $4(3.5)$ & 3.92 & 0.96 & $4(3.3)$ & 4.21 & 0.83 \\
\hline 4 & Care/rehabilitation well planned & $\mathrm{O}$ & $4(3.5)$ & 3.93 & 1.00 & $3(2.5)$ & 4.19 & 0.95 \\
\hline 5 & Thoughtfulness, care for the patient & $\mathrm{Ns} / \mathrm{Ds}$ & $3(2.7)$ & 4.20 & 0.88 & $3(2.5)$ & 4.44 & 0.71 \\
\hline 6 & Seemed professionally competent & $\mathrm{Ns}^{\mathrm{d}} / \mathrm{Ds}$ & $3(2.7)$ & 4.17 & 0.94 & $2(1.6)$ & 4.49 & 0.72 \\
\hline 7 & Information tests, examinations & I & $5(4.4)$ & $3.61^{e}$ & 1.10 & $2(1.6)$ & 4.09 & 0.98 \\
\hline 8 & Took account of family situation & Ns & $3(2.7)$ & 3.79 & 1.02 & $2(1.6)$ & 3.94 & 1.02 \\
\hline 9 & Thoughtfulness, care for relative & $\mathrm{Ns} / \mathrm{Ds}$ & $4(3.5)$ & 3.55 & 1.19 & $1(0.9)$ & 3.93 & 1.03 \\
\hline 10 & Interested in your opinions & Ns/Ds & $3(2.7)$ & 3.47 & 1.17 & $1(0.9)$ & 3.72 & 1.15 \\
\hline 11 & Gave understandable information & $\mathrm{Ns} / \mathrm{Ds}$ & $4(3.5)$ & 3.89 & 1.05 & $1(0.9)$ & 4.17 & 0.93 \\
\hline 12 & Fixed group of other therapists & - & $4(3.5)$ & 4.10 & 0.93 & & & \\
\hline 13 & Felt assure regarding necessary care & - & $4(3.5)$ & 4.02 & 1.13 & & & \\
\hline 14 & Explanation purpose of rehabilitation & - & $3(2.7)$ & 3.67 & 1.11 & & & \\
\hline 15 & Staff committed themselves to patient & - & $3(2.7)$ & 4.05 & 0.95 & & & \\
\hline 16 & Had a fixed contact (rehabilitation) & - & $3(2.7)$ & 3.31 & 1.15 & & & \\
\hline 17 & Provided assistance with the patient & Ns & $6(5.3)$ & 3.90 & 1.02 & & & \\
\hline 18 & Provided coordinated information & - & $4(3.5)$ & 3.73 & 1.07 & & & \\
\hline 19 & Received information about rights & - & $3(2.7)$ & 2.82 & 1.25 & & & \\
\hline \multirow[t]{2}{*}{20} & Informed about what you could contribute with at the hospital & - & $4(3.5)$ & 3.16 & 1.24 & & & \\
\hline & \multicolumn{8}{|l|}{ Discharge period } \\
\hline 1 & Information period after discharge & $\mathrm{Dl}$ & $7(5.7)$ & 3.17 & 1.30 & & & \\
\hline 2 & Felt confident managing follow-up & $\mathrm{Dl}$ & $9(7.4)$ & 3.24 & 1.21 & & & \\
\hline 3 & Informed about what you could do in the event of problems after discharge & $\mathrm{Dl}$ & $9(7.4)$ & 2.81 & 1.38 & & & \\
\hline 4 & Informed about short/long term consequences of head injuries & - & $6(4.9)$ & 2.99 & 1.36 & & & \\
\hline 5 & Consulted during planning discharge ${ }^{e}$ & - & $31(25.4)$ & 3.51 & 1.37 & & & \\
\hline 6 & Necessary arrangements for further rehabilitation ${ }^{e}$ & - & $30(24.6)$ & 3.09 & 1.26 & & & \\
\hline & \multicolumn{8}{|l|}{ Hospital facilities } \\
\hline 1 & Cleanliness & $\mathrm{HF}$ & $6(5.3)$ & 4.32 & 0.85 & & & \\
\hline 2 & Bathroom/shower/toilet facilities & $\mathrm{HF}$ & $5(4.4)$ & 4.14 & 0.90 & & & \\
\hline 3 & Peace and quiet patient's room & $\mathrm{HF}$ & $5(4.4)$ & 4.38 & 0.75 & & & \\
\hline 4 & Meals for the patient & - & $8(7.0)$ & 4.23 & 0.93 & & & \\
\hline 5 & Rest room/accommodation relative(s) & - & $26(23.0)$ & 3.08 & 1.44 & & & \\
\hline 6 & Meals for the relative(s) & - & $22(19.5)$ & 3.60 & 1.36 & & & \\
\hline 7 & Activity provisions for the patient ${ }^{\mathrm{e}}$ & $\mathrm{HF}^{\mathrm{d}}$ & $8(7.0)$ & 3.85 & 1.13 & & & \\
\hline & \multicolumn{8}{|l|}{ Overall single questions about the time in hospital as a whole } \\
\hline 1 & Overall satisfaction with care, treatment and rehabilitation at the hospital & PEPC-S & $2(1.6)$ & 4.36 & 0.82 & & & \\
\hline 2 & Overall satisfaction with the way you were treated as a relative & PEPC-S & $2(1.6)$ & 4.23 & 0.90 & & & \\
\hline 3 & Do you believe that the patient in any way received the wrong treatment? ${ }^{f}$ & PEPC-S & $2(1.6)$ & 4.43 & 0.99 & & & \\
\hline
\end{tabular}


Table 1 Overview of the 51 items divided in main areas and illustrating the corresponding questions asked about the acute and rehabilitation departments (version 1 questionnaire) (Continued)

\begin{tabular}{|c|c|c|c|c|c|}
\hline 4 & Were you angry, distressed, or disappointed with the staff? ${ }^{f}$ & PEPC-S & $2(1.6)$ & 3.78 & 1.32 \\
\hline 5 & Any adverse incidents in connection with transfer between departments ${ }^{f}$ & - & $2(1.6)$ & 3.68 & 1.43 \\
\hline 6 & Were financial needs taken care off? & - & $3(2.5)$ & 2.29 & 1.43 \\
\hline 7 & Were involved children taken care off ( $n=53$ had children involved) & _- & $14(26.4)$ & 3.21 & 1.28 \\
\hline
\end{tabular}

${ }^{a}$ Items and scales are scored $1-5$ where 5 is the best experience

bercentages of missing items are for the acute phase, discharge and single questions calculated from the 122 family members who completed the questionnaire. Percentages for the rehabilitation phase are calculated from the 113 family members who completed questions about the rehabilitation unit

'Parent experience of paediatric care (PEPC) scales: Ns = Nursing services, Ds = Doctor services, $\mathrm{O}=$ Organization, I=Information-examinations and tests,

$\mathrm{DI}=$ Discharge information, $\mathrm{HF}=$ Hospital facilities, $\mathrm{PEPC}-\mathrm{S}=$ single item in addition to the scales in the PEPC questionnaire. $(-)=$ New items in the FECQ

${ }^{d}$ Item removed from the final scale in the PEPC-questionnaire

Item removed from the final scale in the FECQ-TBI

${ }^{\text {f }}$ Scoring corresponds to scoring of other items: higher values represent better results

\section{Statistics}

The statistical analyses were conducted using the SPSS version 22.0. Items with more than $10 \%$ missing were excluded if also supported by consensus in the expert group (to avoid excluding conceptually important items). Consensus meant agreement among the authors AA, UM and CA. Items covering discharge and items regarding hospital facilities were treated as assessing distinct concepts. An exploratory factor analysis (EFA) was used to identify the number of underlying factor structures that adequately summarise the FECQ items. The principal component analysis (PCA) method was preferred in order to capture all variance. The component solution was promax rotated. Components with eigenvalues $>1$ were retained, and loadings $<0.4$ were suppressed. The item distribution indicated that most items were positively skewed and thus not normally distributed. The PCA was therefore based on Spearman's rank-order correlation coefficients, which is a non-parametric method that is less vulnerable to skewed data. Separate PCAs were conducted on a) the 31 items with experiences relating to the acute and rehabilitation departments, b) the six items with experiences relating to discharge, and c) the seven items with experiences relating to hospital facilities (an overview of the items can be observed in Table 1). The overall single-item questions were not topic for factor analysis $[12,13,22]$.

The internal consistency of the identified subscales was evaluated using the Cronbach's alpha coefficient. Values > 0.70 were deemed satisfactory. Construct and criterion related validity was evaluated examining the structural relationships (i.e. correlation coefficients) between the subscale scores and between the subscale scores and the other included measures, respectively [26]. These associations were examined by Spearman's rank correlations.

\section{Results}

\section{Participants}

A total of 171 close family members of patients with severe TBI were contacted by telephone or mail, and 122 completed the questionnaire (response rate $71 \%$ ).
Characteristics of non-participating family members were not available. Regarding patients' characteristics, the proportion of male patients was higher in the participating group (90\%) compared to non-participants $(78 \%)(p<0.05)$. There were no differences in patients' age, marital status, educational level, acute injury severity or functional outcome measured with the Glasgow Outcome Scale Extended [32]. The family members were parents (43\%), spouses/cohabitants $(41 \%)$ or other relatives or close persons $(16 \%)$. The questionnaire data 12 months post-injury were used $(n=117)$. We additionally included five family members who only responded at three months follow-up.

\section{Data quality and missing items}

Table 1 provides descriptive statistics of all the FECQ-TBI items in the version-1-questionnaire (degree of missing items, means and standard deviations). The items asking for experiences with the acute and rehabilitation departments had small percentages of missing data (ranging from 1.6 to $5.3 \%$ ), indicating that all items were endorsed. Two items regarding arrangements for the post-discharge period had substantially higher proportions of missing values $(\geq 25 \%)$ and were therefore excluded (Table 1 , Discharge period, items 5 and 6). Another two items related to hospital facilities for family members had high proportions of missing values (19.5 and 23\%, respectively), but were retained for further analyses due to the lower number of items within this domain (Table 1, Hospital facilities, items 5 and 6).

\section{EFA on the acute and rehabilitation departments' items}

The PCA yielded four components, as shown in Table 2. Two items were excluded due to equally high side-loadings and low loadings, i.e., "one doctor mainly responsible in the acute phase" and "rehabilitation: information about tests and examinations". A second PCA with these two items excluded again yielded four components with eigenvalues $>1$ (Table 3): the first component summarised items related to rehabilitation organisation, collaboration and competence; the second component summarised items related to 
Table 2 Initial factor analysis of all the 31 items related to the acute and rehabilitation phases

\begin{tabular}{|c|c|c|c|c|}
\hline \multirow[b]{2}{*}{ Item } & \multicolumn{4}{|l|}{ Factor loadings $^{a}$} \\
\hline & $\begin{array}{l}\text { 1: } \\
\text { Rehabilitation } \\
\text { Organization, cooperation, } \\
\text { competence }\end{array}$ & $\begin{array}{l}\text { 2: } \\
\text { Acute } \\
\text { Organization and } \\
\text { Information }\end{array}$ & $\begin{array}{l}\text { 3: } \\
\text { Rehabilitation } \\
\text { Information and } \\
\text { Involvement }\end{array}$ & $\begin{array}{l}\text { 4: } \\
\text { Rehabilitation } \\
\text { Organization - } \\
\text { stability }\end{array}$ \\
\hline Re: Felt assure regarding necessary care and rehabilitation & .92 & & & \\
\hline Re: Staff seemed professionally competent & .88 & & & \\
\hline Re: Staff committed themselves to patient & .83 & & & \\
\hline Re: Care and rehabilitation well planned & .83 & & & \\
\hline Re: Thoughtfulness, care for the patient & .81 & & & \\
\hline Re: Staff provided assistance with the patient & .75 & & & \\
\hline Re: Fixed group nurses & .69 & & & \\
\hline Re: Staff provided coordinated information & .67 & & & \\
\hline Re: Staff collaboration & .67 & & & \\
\hline $\begin{array}{l}\text { Re: Adequate explanation about the purpose of the } \\
\text { rehabilitative care }\end{array}$ & .50 & & & \\
\hline Ac: Thoughtfulness, care for the patient & & .87 & & \\
\hline Ac: Staff gave understandable information & & .85 & & \\
\hline Ac: Staff collaboration & & .83 & & \\
\hline Ac: Staff professionally competent & & .82 & & \\
\hline Ac: Fixed group nurses & & .81 & & \\
\hline Ac: Information tests and examinations & & .80 & & \\
\hline Ac: Care and rehabilitation well planned & & .79 & & \\
\hline Ac: Staff took account of family situation & & .71 & .45 & \\
\hline Ac: Thoughtfulness, care for the relative & & .71 & .49 & \\
\hline Ac: Staff interested in your opinions & & .63 & .55 & \\
\hline Re: Thoughtfulness, care for the relative & & & .80 & \\
\hline Re: Informed what you could contribute with & & & .78 & \\
\hline Re: Staff took account of family situation & & & .77 & \\
\hline Re: Staff interested in your opinions & & & .75 & \\
\hline $\begin{array}{l}\text { Re: Information about rights (vocational opportunities, } \\
\text { pensions, insurance, support) }\end{array}$ & & & .62 & \\
\hline Re: Staff gave understandable information & .45 & & .61 & \\
\hline Re: Information tests and examinations ${ }^{b}$ & & & .38 & \\
\hline Re: Had a fixed rehabilitation contact-person & & & & .73 \\
\hline Re: One doctor mainly responsible & & & & .71 \\
\hline Ac: One doctor mainly responsible ${ }^{b}$ & & .58 & & .59 \\
\hline Re: Fixed group of other therapists & & & & .53 \\
\hline
\end{tabular}

Ac Items related to the acute phase (intensive care unit or a surgical department)

$R e$ Items related to in-patient rehabilitation

${ }^{a}$ Factor loadings $<0.4$ are suppressed

${ }^{b}$ Items in Italics was removed before the next factor analysis due to low or cross-loadings

the acute phase; the third component summarised items related to rehabilitation information and the involvement of family members; and the fourth component summarised three items related to rehabilitation organisation/staff stability. As the fourth component contained three items and was theoretically strongly related to the first component, also showing a strong correlation $(r=0.59)$, a final PCA only extracting three components was conducted (Table 4). The items belonging to components 1 and 4 then combined in the first component now covering rehabilitation organization, cooperation and competence, while the second and the third components were the same as in Table 3. 
Table 3 Factor analysis with Principal Component Analysis after removing two non-fitting items of 29 items related to the acute and rehabilitation phase

\begin{tabular}{|c|c|c|c|c|}
\hline \multirow[b]{2}{*}{ Item } & \multicolumn{4}{|l|}{ Factor loadings $^{a}$} \\
\hline & $\begin{array}{l}\text { 1: } \\
\text { Rehabilitation } \\
\text { Organization, cooperation, } \\
\text { competence }\end{array}$ & $\begin{array}{l}\text { 2: } \\
\text { Acute } \\
\text { Organization and } \\
\text { Information }\end{array}$ & $\begin{array}{l}\text { 3: } \\
\text { Rehabilitation } \\
\text { Information and } \\
\text { Involvement }\end{array}$ & $\begin{array}{l}\text { 4: } \\
\text { Rehabilitation } \\
\text { Organization - } \\
\text { stability }\end{array}$ \\
\hline Re: Felt assure regarding necessary care and rehabilitation & .92 & & & \\
\hline Re: Staff seemed professionally competent & .92 & & & \\
\hline Re: Thoughtfulness, care for the patient & .85 & & & \\
\hline Re: Care and rehabilitation well planned & .82 & & & \\
\hline Re: Staff committed themselves to patient & .81 & & & \\
\hline Re: Staff provided assistance with the patient & .75 & & & \\
\hline Re: Staff provided coordinated information & .68 & & & \\
\hline Re: Staff collaboration & .64 & & & \\
\hline Re: Fixed group nurses & .61 & & & \\
\hline $\begin{array}{l}\text { Re: Adequate explanation about the purpose of the } \\
\text { rehabilitative care }\end{array}$ & .50 & & & \\
\hline Ac: Thoughtfulness, care for the patient & & .87 & & \\
\hline Ac: Staff collaboration & & .86 & & \\
\hline Ac: Staff gave understandable information & & .84 & & \\
\hline Ac: Fixed group nurses & & .84 & & \\
\hline Ac: Care and rehabilitation well planned & & .82 & & \\
\hline Ac: Staff seemed professionally competent & & .82 & & \\
\hline Ac: Information tests and examinations & & .81 & & \\
\hline Ac: Staff took account of family situation & & .72 & .44 & \\
\hline Ac: Thoughtfulness, care for the relative & & .72 & .48 & \\
\hline Ac: Staff interested in your opinions & & .63 & .54 & \\
\hline Re: Thoughtfulness, care for the relative & & & .79 & \\
\hline Re: Staff took account of family situation & & & .76 & \\
\hline Re: Informed what you could contribute with & & & .76 & \\
\hline Re: Staff interested in your opinions & & & .74 & \\
\hline $\begin{array}{l}\text { Re: Informed about rights (vocational opportunities, } \\
\text { pensions, insurance, support) }\end{array}$ & & & .60 & .42 \\
\hline Re: Staff gave understandable information & .49 & & .60 & \\
\hline Re: Had a fixed rehabilitation contact-person & & & & .86 \\
\hline Re: One doctor mainly responsible & & & & .76 \\
\hline Re: Fixed group other therapists & & & & .64 \\
\hline Cumulative $\%$ of Variance explained & 49.47 & 64.77 & 71.09 & 75.20 \\
\hline \multicolumn{5}{|l|}{ Component correlation 1: } \\
\hline 2: & .39 & & & \\
\hline 3: & .57 & .45 & & \\
\hline 4: & .59 & .19 & .29 & \\
\hline
\end{tabular}

Ac Items about the acute phase (intensive care unit or a surgical department)

Re Items about the inpatient rehabilitation phase

${ }^{\text {a } F a c t o r ~ l o a d i n g s ~}<0.4$ are suppressed 
Table 4 Factor analysis with Principal Component Analysis and a 3-factor solution with 29 items assessing experiences from the acute and rehabilitation departments

\begin{tabular}{|c|c|c|c|}
\hline \multirow[b]{2}{*}{ Items } & \multicolumn{3}{|l|}{ Factor loadings $^{\mathrm{a}}$} \\
\hline & $\begin{array}{l}\text { 1: } \\
\text { Rehabilitation } \\
\text { Organization, cooperation, } \\
\text { competence, stability }\end{array}$ & $\begin{array}{l}\text { 2: } \\
\text { Acute } \\
\text { Organization and } \\
\text { Information }\end{array}$ & $\begin{array}{l}\text { 3: } \\
\text { Rehabilitation } \\
\text { Information and } \\
\text { Involvement }\end{array}$ \\
\hline Re: Fixed group nurses & .89 & & \\
\hline Re: Care and rehabilitation well planned & .79 & & \\
\hline Re: Staff collaboration & .78 & & \\
\hline Re: Fixed group other therapists & .77 & & \\
\hline Re: One doctor mainly responsible & .75 & & \\
\hline Re: Staff committed themselves to patient & .74 & & \\
\hline Re: Had a fixed rehabilitation contact-person & .74 & & \\
\hline Re: Felt assure regarding necessary care and rehabilitation & .73 & & \\
\hline Re: Staff provided coordinated information & .62 & & \\
\hline Re: Staff seemed professionally competent & .61 & & \\
\hline $\begin{array}{l}\text { Re: Adequate explanation about the purpose of the rehabilitative } \\
\text { care }\end{array}$ & .55 & & \\
\hline Re: Staff provided assistance with the patient & .47 & & \\
\hline Re: Thoughtfulness, care for the patient & .45 & & $.44^{b}$ \\
\hline Ac: Thoughtfulness, care for the patient & & .88 & \\
\hline Ac: Staff collaboration & & .86 & \\
\hline Ac: Staff gave understandable information & & .85 & \\
\hline Ac: Fixed group nurses & & .83 & \\
\hline Ac: Staff seemed professionally competent & & .83 & \\
\hline Ac: Care and rehabilitation well planned & & .82 & \\
\hline Ac: Information tests and examinations & & .81 & \\
\hline Ac: Staff took account of family situation & & .72 & $.45^{b}$ \\
\hline Ac: Thoughtfulness, care for the relative & & .71 & $.46^{b}$ \\
\hline Ac: Staff interested in your opinions & & .62 & $.55^{b}$ \\
\hline Re: Staff took account of family situation & & & .87 \\
\hline Re: Thoughtfulness, care for the relative & & & .85 \\
\hline Re: Staff interested in your opinions & & & .79 \\
\hline Re: Informed what you could contribute with & & & .79 \\
\hline Re: Staff gave understandable information & & & .75 \\
\hline $\begin{array}{l}\text { Re: Staff informed about rights (vocational opportunities, pensions, } \\
\text { insurance, support) }\end{array}$ & & & .54 \\
\hline Cumulative $\%$ of Variance explained & 49.47 & 64.77 & 71.09 \\
\hline Cronbach's alpha & .95 & .94 & .93 \\
\hline \multicolumn{4}{|l|}{ Component correlation 1: } \\
\hline 2: & .33 & & \\
\hline 3: & .57 & .49 & \\
\hline
\end{tabular}

Ac Items assessing the acute phase (intensive care unit or a surgical department)

Re Items assessing the inpatient rehabilitation phase

${ }^{\mathrm{a}}$ Factor loadings $<0.4$ are suppressed

${ }^{b}$ Removed from the final scale 
The items related to the acute phase can be divided into two subscales that correspond to rehabilitation items: acute- organisation, cooperation (5 items; Cronbach's alpha 0.89 ) and acute- information and involvement (5 items; Cronbach's alpha 0.94). This division gives us the ability to compare identical questions of experiences in the acute and rehabilitation departments.

\section{EFA on the discharge and on the hospital facilities items}

The four items asking for experiences related to the discharge period were adequately summarised using a single component (eigenvalue $=2.82, R^{2}=70.4 \%$ ). All items had high loadings (range 0.75-0.88), and the Cronbachs alpha was high $(\alpha=0.86)$. The seven items asking for experiences with hospital facilities during rehabilitation were adequately summarised using a single component, however one item (i.e. "available activities for the patient") was excluded due to a low loading. A new PCA with six items yielded two components (eigenvalues 3.46 and 1.22, $R^{2}=78.0 \%$ ): one patient component regarding patients' experiences with cleaning, bathroom standards, the noise level and food (four items), and a second family member component assessing experiences with food and accommodations (two items). The factor loadings ranged from 0.68-0.95 and the Cronbach's alpha coefficients were 0.86 and 0.80 , respectively. The final developed questionnaire with scoring procedure is available as a Additional file 1. The acute stage item about "one doctor mainly responsible" was kept as a single item but is not included in any of the subscales.

\section{Indications of construct validity}

The correlations between the subscale scores were all positive and statistically significant, as hypothesised (range 0.34-0.80), except a single non-significant correlation between hospital facilities-family and acute organisation and information $(r=0.16)$. See Additional file 2: Table S1. Experiences from the discharge period were moderately to strongly correlated with other scales (0.29-0.66). Overall satisfaction with health care was moderately to strongly significantly related to all subscales (range 0.27-0.57) except hospital facilities-family. Overall satisfaction with family care was significantly correlated to all subscales (correlation coefficients 0.29-0.63), with the strongest correlations to the acute subscales. As expected, the subscales were negatively correlated to incorrect treatment and problems with staff (range -0.12 to -0.45 ). Problems with transfer between departments were negatively correlated to the acute and rehabilitation subscales $(-0.24$ to -0.32$)$ and were not significantly correlated to experiences in the discharge period. Patient age was not significantly correlated to any subscales. The tests supported the validity of the questionnaire.

\section{Discussion}

In this multicentre study of family experiences of care after severe traumatic brain injury, a multidimensional scale was developed and evaluated. The scale was constructed based on a parent experience questionnaire [22] after a review of the literature and interviews with family members to investigate experiences with in-hospital care, treatment and rehabilitation. This is the first multidimensional constructed instrument designed for family members after TBI that measures both general satisfaction and experiences in six dimensions: acute care, rehabilitation-organisation, rehabilitation-information, discharge, hospital facilities- patients and hospital facilities-family. Good psychometric properties were found for the developed instrument.

General questions regarding treatment satisfaction are often given high ratings $[11,17,21]$ and this questionnaire was designed to assess experiences with specific aspects of care that are more useful for quality improvement [16]. The importance of the assessment lies in the consistently positive associations among experiences with care and patient safety, effectiveness and health outcomes [10]. Furthermore, unmet family needs are regularly revealed when investigating the situation of family members to patients with TBI during in-hospital rehabilitation [4,33]. Rotondi et al. (2007) found that families described their needs via phases that paralleled transitions in settings, i.e., acute care, in-patient rehabilitation, returns home and community setting [7]. The new questionnaire FECQ-TBI covers central phases related to in-hospital care.

Many patient and parent satisfaction and experiences questionnaires share common properties and contain the same or corresponding items [14]. To a lesser degree, this is also the case if instruments are not generic, but rather are developed for specific patient groups [13]. Of the domains of general importance for health care services, of great significance is information, an area often found in family satisfaction studies to require improvement [25, 34]. Additionally, instruments on family needs after TBI focus on health information together with support and involvement with care $[33,35]$ : these areas are included in the factor/subscale information in the FECQ-TBI. The second rehabilitation-related factor is organization, which is a significantly important domain for seriously ill patients in the intensive care unit (ICU) and for patients with a long length of stay [36]. Included in the organisation subscale is stability of personnel, in accordance with a qualitative study reporting that sustained connections with professionals are of utmost importance in rehabilitation [37]. Hospital facilities, such as availability and quality of accommodation for family members, was a theme that emerged. In a neonatal ICU a higher standard has been observed to relate to improvements of satisfaction and work quality for the parents [38]. Information regarding the long-term consequences of the injury and post-discharge arrangements for rehabilitation 
was emphasised, in accordance with previous findings [7]. Other items added from the focus group approach related to experiences of feeling safe regarding sufficient care and rehabilitation, the need for explanations regarding the purpose of rehabilitation, the level of staff engagement in the patient's situation and the need for information regarding social security rights. In contrast to family satisfaction instruments designed for ICUs [39], decision-making was not a separate concept in this study. Because most questions added through the focus group and by expert group judgement were of a general character, the final FECQ-TBI could easily be applied to family members to other in-patient rehabilitation categories.

Although the psychometric properties, including construct validity, were good and were at least in line with comparable studies, this study had some limitations. First, the design of this study did not assess test-retest reliability. For now, we must rely on satisfactory findings from the PEPC questionnaire and modifications [22, 27]. Additionally, the focus group could have included a higher number of family members than three to secure a broader covering of themes. Our initial intention to organize a focus group with $4-5$ participants failed of practical reasons. There is a lack of clear evidence based guidance about deciding on sample size, and the usual group size is between 4 and 12 participants [28]. However, the focus group was well prepared and based on a thorough literature search, and used the PEPC as a starting point to develop a structured interview guide. Caregivers varied in respect to strategically important aspects and rich discussions between participants revealed important care experiences. The intention of developing a questionnaire that covers most central care experiences was most probable achieved. Content adequacy and validity could be checked in further studies to assure the usefulness of the questionnaire in countries with different health care pathways and care delivery than Norway [35]. Another possible limitation is that not all suggested scales are based on factor analysis of all of the available items. In line with the practice of other instrument creators, scales can differ from factors and can be based on conceptual considerations when the proposed scales/subscales otherwise fulfil necessary psychometric properties [13, 22]. A further limitation is the number of items with high proportions of missing data. To avoid losing all information on the family members' experiences with hospital facilities, we choose to keep two items despite their high levels of missing data. Although the proportion of missing data was high due to limited relevance for all family members, we concluded that the dimension was important for many families with patients experiencing long hospital stays $[25,38]$. However, to further establish the questionnaires validity and utility use in other real-world samples would be preferable.

The strengths of this study are its multicentre national design and the relatively high questionnaire response rate of $71 \%$, which is higher than in comparable studies (range $44-55 \%)[22,27,39,40]$. The higher response rate is explained by the fact that severe TBI patients and their family members have a closer connection to a hospital than do other patients and relatives participating in hospital surveys. Examination of differences between respondent and nonrespondent caregivers was not possible as data on nonrespondent caregivers was not available. However, patientrelated characteristics were similar in the respondent and non-respondent group, except a small difference in the proportion of male patients, supporting representativeness.

\section{Conclusions}

The FECQ-TBI includes important experiences of care related to in-hospital treatment phases. The questionnaire has high data quality, internal consistency and construct validity and can be used in hospitals with rehabilitation departments for quality improvement.

\section{Additional files}

Additional file 1: The Family Experiences of in-hospital Care Questionnaire in severe Traumatic Brain Injury (FECQ-TBI) - final version. (PDF 75 kb)

Additional file 2: Table S1. Internal correlations among subscale scores and correlations with single- items questions. (DOCX 17 kb)

\section{Acknowledgements}

Staff at the TBI-specialised rehabilitation departments in Norway at the Sørlandet Hospital, Kristiansand; The Oslo University Hospital, Oslo; the Sunnaas Rehabilitation Hospital, Nesodden; the St.Olavs Hospital, Trondheim; the Haukeland University Hospital, Bergen, and the University Hospital of North Norway, Tromsø, recruited participants to the study. Hege Teslo supported in data collection.

\section{Funding}

This study was conducted with grants from the North Norwegian Health Authorities, grant number 8744/SFP1108-13.

\section{Availability of data and materials}

The questionnaire developed in the study is available in Additional file 1. The dataset analysed during the current study is available from the corresponding author on reasonable request, without breaching participant confidentiality.

\section{Authors' contribution}

AA, USM and CA contributed to the study design, acquisition of data, analysis and interpretation of data and drafting of the manuscript. CR participated in the design of the study, interpretation of data and drafting of the manuscript. OF participated to the statistical analysis and interpretation of data and drafting of the manuscript. All authors read and approved the final manuscript.

\section{Competing interests}

The authors declare that they have no competing interests.

Consent for publication

Not applicable.

\section{Ethics approval and consent to participate}

Informed consent was collected from all family members participating in this study. The patients also provided consent regarding the contact with their relatives. The study was approved by the Regional Committee for Medical Research Ethics South-East Norway (REK South-East D (2009/702). 


\section{Author details}

'Department of Rehabilitation, University Hospital of North Norway, Sykehusvn.1, 9038 Tromsø, Norway. ${ }^{2}$ Faculty of Health Sciences, Department of Clinical Medicine, UiT The Arctic University of Norway, Troms $\emptyset$, Norway. ${ }^{3}$ Faculty of Health Sciences, Department of Health and Care Sciences, UiT The Arctic University of Norway, Troms $\varnothing$, Norway. ${ }^{4}$ Faculty of Health Sciences, Department of Psychology, UiT The Arctic University of Norway, Tromsø, Norway. ${ }^{5}$ Department of Physical Medicine and Rehabilitation, Oslo University Hospital, Oslo, Norway. Institute of Health and Society, Research Centre for Habilitation and Rehabilitation Models and Services (CHARM), Faculty of Medicine, University of Oslo, Oslo, Norway.

Received: 19 November 2015 Accepted: 28 October 2016 Published online: 28 November 2016

\section{References}

1. Stelfox HT, Boyd JM, Straus SE, Gagliardi AR. Developing a patient and familycentred approach for measuring the quality of injury care: a study protocol. BMC Health Serv Res. 2013;13:31.

2. Dodek PM, Heyland DK, Rocker GM, Cook DJ. Translating family satisfaction data into quality improvement. Crit Care Med. 2004;32(9):1922-7.

3. Arango-Lasprilla JC, Ketchum JM, Dezfulian T, Kreutzer JS, O'Neil-Pirozzi TM Hammond F, Jha A. Predictors of marital stability 2 years following traumatic brain injury. Brain Inj. 2008;22(7-8):565-74.

4. Kolakowsky-Hayner SA, Miner KD, Kreutzer JS. Long-term life quality and family needs after traumatic brain injury. J Head Trauma Rehabil. 2001;16(4):374-85.

5. Perlesz A, Kinsella G, Crowe S. Psychological distress and family satisfaction following traumatic brain injury: injured individuals and their primary, secondary, and tertiary carers. J Head Trauma Rehabil. 2000;15(3):909-29.

6. Manskow US, Sigurdardottir S, Roe C, Andelic N, Skandsen T, Damsgard E, Elmstahl S, Anke A. Factors Affecting Caregiver Burden 1 Year After Severe Traumatic Brain Injury: A Prospective Nationwide Multicenter Study. J Head Trauma Rehabil . 2015;30(6):411-23.

7. Rotondi AJ, Sinkule J, Balzer K, Harris J, Moldovan R. A qualitative needs assessment of persons who have experienced traumatic brain injury and their primary family caregivers. J Head Trauma Rehabil. 2007;22(1):14-25.

8. Stelfox HT, Perrier L, Straus SE, Ghali WA, Zygun D, Boiteau P, Zuege DJ. Identifying intensive care unit discharge planning tools: protocol for a scoping review. BMJ open. 2013;13:31.

9. Norup A, Petersen J, Mortensen EL. Relatives of patients with severe brain injury: Growth curve analysis of anxiety and depression the first year after injury. Brain Inj. 2015;29(7-8):822-9.

10. Doyle C, Lennox L, Bell D. A systematic review of evidence on the links between patient experience and clinical safety and effectiveness. BMJ open. 2013;3:e001570. 10.1136.

11. Crow R, Gage H, Hampson S, Hart J, Kimber A, Storey L, Thomas H. The measurement of satisfaction with healthcare: implications for practice from a systematic review of the literature. Health Technol Assess. 2002;6(32):1-244.

12. Pettersen Kl, Veenstra M, Guldvog B, Kolstad A. The Patient Experiences Questionnaire: development, validity and reliability. Int J Qual Health Care. 2004;16(6):453-63.

13. Iversen $\mathrm{HH}$, Holmboe $\mathrm{O}$, Bjertnaes OA. The Cancer Patient Experiences Questionnaire (CPEQ): reliability and construct validity following a national survey to assess hospital cancer care from the patient perspective. BMJ Open. 2012;2:e001437. 10.1136

14. Bjertnaes OA, Sjetne IS, Iversen $\mathrm{HH}$. Overall patient satisfaction with hospitals: effects of patient-reported experiences and fulfilment of expectations. BMJ Qual Saf . 2012;21(1):39-46.

15. Williams B. Patient satisfaction: a valid concept? Soc Sci Med. 1994;38(4):509-16

16. Cleary PD, Edgman-Levitan S, McMullen W, Delbanco TL. The relationship between reported problems and patient summary evaluations of hospital care. QRB Qual Rev Bull . 1992;18(2):53-9.

17. Becker F, Kirmess M, Tornas S, Lovstad M. A description of cognitive rehabilitation at Sunnaas Rehabilitation Hospital-balancing comprehensive holistic rehabilitation and retraining of specific functional domains. NeuroRehabilitation. 2014;34(1):87-100.

18. Anke A, Andelic N, Skandsen T, Knoph R, Ader T, Manskow U, Sigurdardottir S, Roe C. Functional Recovery and Life Satisfaction in the First Year After Severe Traumatic Brain Injury: A Prospective Multicenter Study of a Norwegian National Cohort. J Head Trauma Rehabil. 2015;30(4):E38-49.
19. Arntzen C, Borg T, Hamran T. Long-term recovery trajectory after stroke: an ongoing negotiation between body, participation and self. Disabil Rehabil. 2015;37(18):1626-34

20. Heyland DK, Tranmer JE. Kingston General Hospital ICURWG: Measuring family satisfaction with care in the intensive care unit: the development of a questionnaire and preliminary results. J Crit Care. 2001;16(4):142-9.

21. Epstein D, Unger JB, Ornelas B, Chang JC, Markovitz BP, Dodek PM, Heyland DK, Gold Jl. Satisfaction with care and decision making among parents/ caregivers in the pediatric intensive care unit: a comparison between English-speaking whites and Latinos. J Crit Care. 2015;30(2):236-41.

22. Garratt AM, Bjertnaes OA, Barlinn J. Parent experiences of paediatric care (PEPC) questionnaire: reliability and validity following a national survey. Acta Paediatr. 2007:96(2):246-52

23. Solheim E, Garratt AM. Parent experiences of inpatient pediatric care in relation to health care delivery and sociodemographic characteristics: results of a Norwegian national survey. BMC Health Serv Res. 2013;13:512.

24. Mitchell-Dicenso A, Guyatt G, Paes B, Blatz S, Kirpalani H, Fryers M, Hunsberger M, Pinelli J, Van Dover L, Southwell D. A new measure of parent satisfaction with medical care provided in the neonatal intensive care unit. J Clin Epidemiol. 1996;49(3):313-8.

25. Schwarzkopf D, Behrend S, Skupin H, Westermann I, Riedemann NC, Pfeife R, Gunther A, Witte OW, Reinhart K, Hartog CS. Family satisfaction in the intensive care unit: a quantitative and qualitative analysis. Intensive Care Med. 2013:39(6):1071-9.

26. Mokkink LB, Terwee CB, Knol DL, Stratford PW, Alonso J, Patrick DL, Bouter $\mathrm{LM}$, de Vet HC. The COSMIN checklist for evaluating the methodological quality of studies on measurement properties: a clarification of its content. BMC Med Res Methodol. 2010;10:22.

27. Garratt AM, Bjertnaes OA, Holmboe O, Hanssen-Bauer K. Parent experiences questionnaire for outpatient child and adolescent mental health services (PEQ-CAMHS Outpatients): reliability and validity following a national survey. Child Adolesc Psychiatry Ment Health. 2011;5:18.

28. Carlsen B, Glenton C. What about N? A methodological study of sample-size reporting in focus group studies. BMC Med Res Methodol. 2011;11:26.

29. Malterud K. Systematic text condensation: a strategy for qualitative analysis. Scand J Public Health. 2012;40(8):795-805

30. Kreuger FA, Beerman $\mathrm{H}$. The screening history of women with cervical cancer in the Rotterdam area. Eur J Epidemiol. 2000;16(7):641-5.

31. Andelic N, Anke A, Skandsen T, Sigurdardottir S, Sandhaug M, Ader T, Roe C. Incidence of hospital-admitted severe traumatic brain injury and in-hospital fatality in Norway: a national cohort study. Neuroepidemiology. 2012;38(4): 259-67.

32. Wilson JT, Pettigrew LE, Teasdale GM. Structured interviews for the Glasgow Outcome Scale and the extended Glasgow Outcome Scale: guidelines for their use. J Neurotrauma. 1998;15(8):573-85.

33. Serio CD, Kreutzer JS, Witol AD. Family needs after traumatic brain injury: a factor analytic study of the Family Needs Questionnaire. Brain Inj. 1997;11(1):1-9.

34. Wang MC, Mosen D, Shuster E, Bellows J. Association of patient-reported care coordination with patient satisfaction. J Ambul Care Manage. 2015; 38(1):69-76.

35. Norup A, Perrin PB, Cuberos-Urbano G, Anke A, Andelic N, Doyle ST, Cristina Quijano M, Caracuel A, Mar D, Guadalupe Espinosa Jove I, et al. Family needs after brain injury: A cross cultural study. NeuroRehabilitation. 2015; 36(2):203-14.

36. Dodek PM, Wong H, Heyland DK, Cook DJ, Rocker GM, Kutsogiannis DJ, Dale C, Fowler R, Robinson S, Ayas NT, et al. The relationship between organizational culture and family satisfaction in critical care. Crit Care Med. 2012;40(5):1506-12.

37. Schreiber J, Benger J, Salls J, Marchetti G, Reed L. Parent perspectives on rehabilitation services for their children with disabilities: a mixed methods approach. Phys Occup Ther Pediatr. 2011:31(3):225-38.

38. Watson J, DeLand M, Gibbins S, MacMillan York E, Robson K. Improvements in staff quality of work life and family satisfaction following the move to single-family room NICU design. Adv Neonatal Care. 2014;14(2):129-36.

39. Wall RJ, Engelberg RA, Downey L, Heyland DK, Curtis JR. Refinement, scoring, and validation of the Family Satisfaction in the Intensive Care Unit (FS-ICU) survey. Crit Care Med. 2007;35(1):271-9.

40. Oltedal S, Garratt A, Bjertnaes O, Bjornsdottir M, Freil M, Sachs M. The NORPEQ patient experiences questionnaire: data quality, internal consistency and validity following a Norwegian inpatient survey. Scand J Public Health. 2007;35(5):540-7. 